\title{
Reverse VSP and Crosswell Seismic Imaging at the Savannah River Site
}

by

R. J. Cumbest

Westinghouse Savannah River Company

Savannah River Site

Aiken, South Carolina 29808

J. O. Parra

Southwest Research Institute

TX USA

B. J. Zook

Southwest Research Institue

TX USA

C. Addington

Tomoseis Institute

TX USA

V. Price

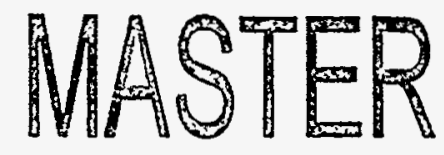

A document prepared for SOCIETY OF EXPLORATION GEOPHYSICS EXTENDED ABSTRACTS GEOPHYSICS at Denver from 04/15/96 - 04/15/96.

\section{DOE Contract No. DE-AC09-89SR18035}

This paper was prepared in connection with work done under the above contract number with the U.S. Department of Energy. By acceptance of this paper, the publisher and/or recipient acknowledges the U.S. Government's right to retain a nonexclusive, royalty-free license in and to any copyright covering this paper, along with the right to reproduce and to authorize others to reproduce all or part of the copyrighted paper. 


\section{DISCLAIMER}

Portions of this document may be illegible in electronic image products. Images are produced from the best available original document. 


\section{DISCLAIMER}

This report was prepared as an account of work sponsored by an agency of. the United States Government. Neither the United States Government nor any agency thereof, nor any of their employees, makes any warranty, express or implied, or assumes any legal liability or responsibility for the accuracy, completeness, or usefiiness of any information, apparatus, product, or process disclosed, or represents that its use would not infringe privately owned rights. Reference herein to any specific commercial product, process, or service by trade name, trademark, manufacturer, or otherwise does not necessarily constitute or imply its endorsement. recommendation, or favoring by the United States Government or any agency thereof. The views and opinions of authors expressed herein do not necessarily state or reflect those of the United States Government or any agency thereof.

This report has been reproduced directly from the best available copy.

Available to DOE and DOE contractors from the Office of Scientific and Technical Information, P.O. Box 62, Oak Ridge, TN 37831; prices available from (615) 57.6-8401.

Available to the public from the National Technical Information Service, U.S. Department of Commerce, 5285 Port Royal Road, Springfield, VA 22161. 


\section{REVERSE VSP AND CROSSWELL SEISMIC IMAGING AT THE SAVANNAH RIVER SITE}

by

J. O. Parra

B. J. Zook

C. Addington

R. J. Cumbest

V. Price

February 1996 


\begin{abstract}
Analysis of crosswell and three-component seismic data integrated with well logs have produced information on the distribution of subsurface heterogeneities below the In-Tank Precipitation facility at the Savannah River Site (SRS). The travel time P-wave tomogram and reflection imaging delineate lateral and vertical structural details of the formations. In particular, the high-resolution P-wave tomogram captures a low-velocity zone within the carbonates. This zone is surrounded by reflection events between depths of 150 and $200 \mathrm{ft}$ in the reflection imaging. The reflections are caused by the acoustic impedance contrast between the low velocity zone of "soupy" sand mixtures of unconsolidated materials and the more rigid and dense competent surrounded medium. The time-frequency analysis of full waveforms particle velocity identifies guided waves in form of leaky and normal modes at the depths of about 138 to $150 \mathrm{ft}$. This resulting change in lithology associated with the presence of guided waves is consistent with a velocity low observed in the vertical velocity profile determined from the inversion of three-component seismic data. This low-velocity zone intercepted by the wells H-BOR-34 and H-BOR-50 correlates with the conductive Griffins Landing Member, which is located above the carbonates. The result of the experiments demonstrate that the present high-resolution crosswell seismic measurement technique (using frequencies up to $1500 \mathrm{~Hz}$ ) meets the resolution requirements to map geological and geotechnical targets in the vicinity of the In-Tank Precipitation facility at the Savannah River Site.
\end{abstract}




\section{INTRODUCTION}

Adequate characterization techniques are needed to meet the ultimate goal of evaluating the seismic and structural safety of existing and planned facilities at the Savannah River Site (SRS). In particular, methodologies and technologies are needed to satisfy the resolution requirements for specific geologic and geotechnical targets in the vicinity of the In-Tank Precipitation/Extended Sludge Processing Facility and H-Tank Farm areas of SRS.

The geologic setting at the SRS is in unlithified to poorly lithified upper Coastal Plain sediments in South Carolina. The carbonate bodies of interest are stratigraphically confined, typically discrete bodies from 80 to $150 \mathrm{ft}$ depth. The hydrologic confining units in this setting are typically non-fissile clay strata. These units may or may not be faulted. In particular, a technique is needed to resolve the extent and boundaries of the carbonate bodies in addition to the presence of internal voids and high porosity zones.

Crosswell seismic techniques hold promise of investigating the sediment properties (e.g. porosity, permeability, density, etc.) while also depicting its heterogeneous structural features (e.g. boundaries, faults, internal voids, etc.). High-resolution seismic measurements between two or more boreholes may be an efficient tool for resolving the geological structures at SRS. Traveltime tomography inversion application can be used in estimating the compressional wave velocity distribution between boreholes. Direct arrival time data selected from interwell seismic measurements represent only a small portion of the seismic events contained in a seismic section. Reflection events observed in full waveforms may be appropriate for resolving the layered structure in the target zone of interest at the SRS. In fact, interwell seismic reflection data acquired with a piezoceramic source have been analyzed and processed using state-of-the-art mapping techniques to produce high- 
resolution of the subsurface geology at the Devine test site, near San Antonio, Texas, as reported by Lazaratos, et al (1994).

Substantial developments have been made recently in seismic sources, receivers and processing techniques (Hardage, 1992; Chen et al., 1990; Kennedy et al., 1988; Laurent et al., 1990; Chen, 1993; Balogh et al., 1988; and Becquey et al., 1992). The geological conditions at the Savannah River Site (SRS) present unique geotechnical problems for the applicability of highresolution interwell seismic techniques (i.e., crosswell tomography and reverse verticl seismic profiling). Because of the potential use of high-resolution seismic techniques for mapping heterogeneous geological formations, it is anticipated that this technology may be appropriate for the characterization of the subsurface geology for the evaluation of existing and planned facilities. The objective of this work is to evaluate the applicability of a 1200 -joule arc discharge borehole seismic source and a piezoceramic source to conduct crosswell experiments and reverse vertical seismic profiling at the SRS and to select the appropriate technology/methodology to image geological and geotechnical features beneath SRS facilities in support of engineering studies. The principal application of these seismic measurements is to investigate the propagation characteristics of seismic waves in a target zone formed by carbonate bodies, clay beds and loosely consolidated sands at the SRS. The processing efforts included the inversion of travel-time data to be used to produce compressional wave velocity, distributions (tomograms) from multiple offset seismic measurements using the arc-discharge source and the piezoceramic source. In addition, reflection imaging from multiple offsets seismic measurements is produced to determine the presence of interfaces or thin beds within the target zone of interest. Furthermore, reverse VSP velocity distributions are produced and integrated with the geology and compared with the reflection imaging to evaluate the borehole seismic technology. 


\section{Geological Setting}

The in-tank precipitation facility (ITP) is in the Savannah River site, which is located about 20 miles southeast of the fall-line within the Upper Atlantic Coastal Plain of South Carolina and Georgia (see Figure 1). The stratigraphic formations that are encountered in the upper $300 \mathrm{ft}$ of sediments in the ITP area are shown in Figure 2. In ascending order this cross section includes: the Congaree Formation, Santee Formation, Griffins Landing member of the Dry Branch Formation, Dry Branch Formation and the Tobacco Road Formation.

The Congaree Formation is located above the Paleocene strata. The upper Congaree consists of moderately to well-sorted, fine to coarse quartz sands. Thin clay laminae are present in places. According to Snipes et al. (1993) going upward across the Williamsburg/Congaree contact, the sands become cleaner, and clay bed thickness decreases. Above the Congaree formation is the middle Eocene Santee Limestone Formation which is composed of lithofacies. For example, in the siliclastic facies (going upward from the Santee/Congaree contact) the grain size decreases, the green clays become more common, and heavy minerals become abundant. A pebbly zone occurs at the base in places, which is referred as the "green clay" at the SRS. In the southeastern part of the site, Santee carbonates interfinger with laminated calcilutite, calcarenite, and calcareous silt and clay.

The Dry Branch Formation and Tobacco Road Formation constitute the upper Eocene at SRS. Part of the Dry Branch Formation consists of the calcareous Griffins Landing Member, composed of calcilutite, calcarenite, bioclastic and biomoldic limestone, calcareous sand, and shelly and calcareous clay. The upper Dry Branch Formation is made up of the Irwington Sand Member. It is composed of moderately sorted quartz sand, with interlaminated and interbedded clays, typically tan, abundant in places. Pebbly layers and zones rich in clay clasts occur. Irwington sands are 
generally coarser than those of the underlying Santee siliciclastics, and glauconite and heavy minerals are less abundant.

The Late Eocene Tobacco Road Formation conformally overlies the Dry Branch Formation. The base of the unit is marked by a coarse layer that in places can contain flat quartz pebbles. The formation consists of moderately to poorly sorted quartz sands. The Tobacco Road Formation crops out over much of the southwestern South Carolina Plain and is widely exposed at the SRS.

\section{The Borehole Layout and the Well Logs}

In order to conduct crosswell seismic experiments WSRC drilled five $300 \mathrm{ft}$ deep boreholes which surround the Tank 51 area. The wells penetrate the Tertiary sands and limestones. The location of these wells is given in Figure 3. The well logs available for this project are from wells $\mathrm{H}$ BOR-34, H-BOR-50, H-BOR-44, and HTF-B-1.

The well logs recorded in wells H-BOR-34, H-BOR-50, and H-BOR-44 are correlated with the geologic cross section shown in Figure 2, using the above lithologic descriptions. The resistivity logs between 250-300 ft. given in Figure 4 show that there is an increase in resistivity going upward across the Congaree/Williamsburg contact. At the same time the gamma ray count (shown in Figure 5) decreases, which corresponds to much cleaner sands. This high resistivity anomaly is shown in the three wells. In general, the resistivity of wells H-BOR-44 and H-BOR-50 are very similar, which indicates that the geologic units between those wells are connected. Alternatively, the difference of resistivity signatures with respect to well H-BOR-34 indicates that the Santee Limestone is not intercepted by well H-BOR-34.

In addition, the well logs in the three wells show that the Santee/Congaree contact is associated with a low-resistivity zone, which corresponds to the green clay layer. This thin conductive zone correlates with a high gamma ray count. The Santee Formation is associated with 
a large low-resistivity anomaly having higher resistivity than that associated with the green clay layer. A second low-resistivity zone is observed in the three wells above the Santee Formation which is associated with the tan clay thin layer which separates the Dry Branch Formation from the Santee Limestone Formation. In addition, the tan clay layer correlates with a low-velocity anomaly observed in wells H-BOR-44 and H-BOR-50.

In summary, the low-resistivity signatures associated with the tan clay (above the Santee) and the green clay (below the Santee) can be observed in the short normal, long normal and guard resistivity logs recorded in the three wells. In addition the tan clay layer correlates with a low compressional wave velocity observed in well logs recorded in wells H-BOR-44 and H-BOR-50. The presence of this low-velocity layer is not evident in the compressional wave velocity log of well $\mathrm{H}-$ BOR-34 (Parra et al., 1995).

\section{The Geological Problem}

Underneath the ITP facility there are soft zones associated with the apparent dissolutioning of calcareous sediments. The purpose of the geophysical measurements is aimed at characterizing the subsurface below Tank 51 based on the following two main issues: (1) The carbonate is not a continuous geologic unit in its lateral extent. In this case the objective is to delineate the edge of the transition zone. Geologists believe the transition zone may be a fairly rapid termination, possibly due to faulting or dissolutioning. The carbonate exists at about an elevation of 150-200 feet (MSL) and is about $20-50$ feet thick. The limestone has a P-wave velocity of about $10,000 \mathrm{ft} / \mathrm{s}$, and the surrounding material has a P-wave velocity of $5000 \mathrm{ft} / \mathrm{s}$; and (2) soft zones or cavities associated with the calcareous sediments are present in the formation. The successful application of crosswell seismic measurements technique will be to demonstrate if the soft zones/cavities in the calcareous sediments can be detected and characterized 


\section{FIELD EXPERIMENTS AT THE SAVANNAH RIVER SITE}

The main objective of the field experiments was to record crosswell seismic and reverse VSP data simultaneously between a source borehole and at least two detector boreholes. A diagram of the proposed experiments for crosswell tomography and a reverse VSP is shown in Figure 3. Multiple source-detector measurements were conducted using different source and receiver instrumentation. Crosswell measurements between wells $\mathrm{H}-\mathrm{BOR}-34$ and well $\mathrm{H}-\mathrm{BOR}-50$ were recorded with the TomoSeis piezoceramic source. As a result one crosswell profile was produced in two days of work (12 hour shifts). A second experiment was done by placing a 3-component shuttle sonde (the borehole shuttle is a wall locking sonde containing three geophones) in well $\mathrm{H}$ BOR-50, leaving the arc-discharge source in well H-BOR-34.

The operation started by conducting noise test and spectral analysis of a few traces. After reviewing the data quality recorded with the hydrophones and the 3-component geophones, we decided that a total of eight stacks of the signal will be appropriate for accomplishing our objectives. The 3-component shuttle sonde was placed in well H-BOR-50 at the depth of $200 \mathrm{ft}$. The control unit to operate the shuttle was installed and operated in the recording truck.

Since the borehole casings were made of metal at the SRS, the magnetic unit that rotates the shuttle before it is clamped was not installed. Alternatively, we have determined the orientation of the particle motion at each source position using a numerical algorithm. The application of the technique is given in the data processing section of this report.

The 3-component data was acquired by firing the source eight times and moving the source every $1 / 2 \mathrm{~m}$. Once the source was moved 147 times in well H-BOR-34, the 3 -component shuttle was moved 10 feet. A total of eight detector positions were recorded once the experiments were completed. 


\section{DATA PROCESSING AND ANALYSIS}

\section{Processing of 3- Component Interwell Seismic Data}

The 3-component detector data recorded using the 1200-Joule arc-discharge source was analyzed for the presence of shear waves. The 3-component data was processed by rotating the seismograms recorded at the Savannah River Site using several processing methods (see Parra, 1995). Also F-K filtering was applied to some of the 3-component seismic data to suppress undesirable events that obstruct the view of more important reflections.

The analysis of the 3-component seismic data suggested that converted and direct shear waves are strongly attenuated by the presence of fluid in the formation. As a consequence, direct shear wave energy may be required for the propagation of shear wave in the formations at the SRS. We believe that a shear source will be more appropriate to use for the generation of direct shear waves. If shear waves propagate in the fluid-filled porous saturated formation a 3-component detector tool coupled to the formation should be used to capture the particle motion of the shear wave polarization in the different directions.

After the rotation of 3-component common detector seismograms we have observed trapped energy (or channel waves) for the detector placed above the Santee Limestone Formation at a depth of 140 feet. The trapped energy (or channel waves) can be used as an indicator of the connectivity or continuity of low-velocity zones. As a consequence the waveforms recorded within these lowvelocity zones were analyzed, in particular time-frequency and group velocity contour plots were analyzed to identify the events that may be associated with leaky and normal modes.

\section{Time-Frequency Analysis}

The interwell seismic data contains several different events, which can be seen as different arrivals in the full waveforms. These various events, such as P-waves, shear waves, and tube waves, 
generally have very different spectral content as well. One way of analyzing signals is to examine how the spectral content of the signal varies in time (within the signal). We do this using timefrequency analysis, which shows the spectrum as a function of time. This technique is particularly useful in detecting guided waves, which exhibit velocity dispersion (velocity is a function of frequency). Such dispersion is apparent in time-frequency plots.

There are many time-frequency methods. The one we have used in our analysis of the Savannah River triaxial data is the spectrogram, which is just the squared magnitude of the short-time Fourier transform. Descriptions of other techniques can be found in the literature (Cohen, 1989; Hlawatsch and Boudreaux-Bartels, 1992; Zook, 1994).

We are using time-frequency analysis to examine the data for evidence of trapped guided waves, indicating continuous low-velocity layers. Locating such channels helps us determine the lithology as well as identify layers of interest (e.g. porous and fluid flow transport layers or impermeable layers), (Parra and Xu, 1994).

The data analyzed in this section is the horizontal particle velocity component, which was recorded for the receiver stationed at a depth of $140 \mathrm{ft}$, and the source moving at increments of 1.5 $\mathrm{ft}$, in a well H-BOR-34. A portion of this common receiver seismogram is shown in Figure 6 . The time-frequency representation of all the traces were produced to identify regions in which timefrequency signatures are similar. Our primary assumption in this case is that these regions corresponds to lithology changes. Since space does not allow us to show time-frequency plots of all the traces, we present below those plots that are representative of three regions of interest.

The first region corresponds to source positions below $150 \mathrm{ft}$, the second region is for source positions between $150 \mathrm{ft}$ and $138 \mathrm{ft}$, and the third region is for source positions above $138 \mathrm{ft}$. For example, when the source is stationed at $160.5 \mathrm{ft}$, we observed a direct event ( $\mathrm{P}$-wave) at about 
$25 \mathrm{~ms}$ in the frequency interval of 100 to $700 \mathrm{~Hz}$ (see Figure 7a). We also observed a low frequency event $(200 \mathrm{~Hz})$ arriving at about $100 \mathrm{~ms}$. As the source moves up in the borehole, we selected a second trace which was recorded at the source position of $145.5 \mathrm{ft}$ (see Figure 7b). The time frequency representation of this trace shows that the direct event is split in three parts, a low, an intermediate (about $500 \mathrm{~Hz}$ ) and a high frequency contour. The high-frequency energy observed above $700 \mathrm{~Hz}$ corresponds to background noise. Alternatively, the energy captured below $200 \mathrm{~Hz}$ ( which arrives after $30 \mathrm{~ms}$ ) corresponds to reflection events and tube waves. In addition, Figure $7 \mathrm{~b}$ shows two time-frequency contours of $500 \mathrm{~Hz}$ at $75 \mathrm{~ms}$ and $100 \mathrm{~ms}$. A similar time-frequency signature (given in Figure 7c) is produced when the source is moved at $138 \mathrm{ft}$. In this case the contour (or an event) at $100 \mathrm{~ms}$ is much larger than that shown in the previous Figure $7 \mathrm{~b}$.

Next, if we focus in those three contours of about $500 \mathrm{~Hz}$ (as is shown in Figure 7d) associated with a source placed at a depth of $129 \mathrm{ft}$ feet, the signatures arriving at $25 \mathrm{~ms}$ have merged into one contour, and the other two signatures arriving at $75 \mathrm{~ms}$ and $100 \mathrm{~ms}$ have changed their characteristics. This analysis suggests that the change in signature (i.e., when the signature split in two major contours), as the source moves upward is associated with a change in lithology that occurs approximately between the depths of $138 \mathrm{ft}$ and $150 \mathrm{ft}$. This lithology of interest corresponds to a low-velocity zone that trapped energy as the waves propagate between the source and detector boreholes. In fact, the event arriving at $25 \mathrm{~ms}$ at the frequency of $500 \mathrm{~Hz}$ is a leaky mode and the event arriving at about $100 \mathrm{~ms}$ (having the same frequency of $500 \mathrm{~Hz}$ ) is a shear wave followed by a normal mode. This last event shows dispersion in the range of $500-600 \mathrm{~Hz}$, which proves a lowvelocity region has been identified between the depths of 138-150 ft using time-frequency analysis. In addition, a boundary is detected in the logs at $150 \mathrm{ft}$, which is consistent with the bottom boundary of a velocity low in the vertical velocity distribution observed in Figure 8. 


\section{P-wave Tomography and P-wave Reflection Imaging}

The field data was edited and the first arrival travel times were picked. These first arrival times were input to a travel time inversion algorithm to produce a $\mathrm{P}$-wave velocity tomogram. The data was initially inverted by constraining the velocity function to one dimension. Additional iterations were performed allowing progressively more freedom by reducing the horizontal bin size to a point where artifacts of the inversion begin to dominate the velocity function. The inversion process was stopped at this point to produce the final P-wave velocity tomogram.

The data prepared for the velocity tomogram was used to generate a reflection image of the interwell area. A velocity model was generated by interactively raytracing and modifying a velocity model until the predicted first arrival times matched the first arrivals of the data within less than $1 \mathrm{~ms}$. Coherent arrivals which do not represent reflection events were filtered from the data (wavefield separation), and the resulting reflection data were VSP-CDP mapped. These mapped data have their reflection energy positioned correctly in the interwell area. The mapped data are then sorted on reflection incidence angle, and stacked over the optimal angle range.

The difficulty of wavefield separation for this profile is the tube wave removal. As we can see from the full wavefield data displays that the P-wave reflection moveouts are very close to the tube wave moveout because the $\mathrm{P}$-wave velocity is close to the tube wave velocity (see Figure 9). This causes some inseparable tube wave residuals left behind when the P-wave reflections are preserved.

\section{INTERPRETATION}

\section{Integration of Geophysical, Geological and Well Log Data}

Since resistivity and gamma ray logs are valuable information we combined these logs recorded in wells $\mathrm{H}-\mathrm{BOR}-34, \mathrm{H}-\mathrm{BOR}-50$, and $\mathrm{H}-\mathrm{BOR}-44$ to estimate the petrophysical boundaries. 
The logs shown in Figures 4 and 5 were used to correlate the petrophysical boundaries at the borehole scale with the interwell seismic results. As we previously discussed, the well logs indicated that the Santee/Congaree contact is associated with a low-resistivity anomaly and a high gamma ray count which represents the effect of the green clay layer at a depth of about $210 \mathrm{ft}$. Furthermore, this geologic unit correlates with a compressional wave velocity low in the P-wave velocity profile (see Figure 8) which was produced from the 3-component seismic data using an algorithm developed by Jackson and Tweeton (1994).

In addition, a second low-resistivity anomaly is observed in the three wells above the Santee Formation at depths of $140 \mathrm{ft}$ to $150 \mathrm{ft}$. This conductive zone separates the Dry Branch Formation from the Santee carbonates and correlates with a compressional wave velocity low in the P-wave velocity profile. We believe that this low-velocity zone corresponds to a conductive clay layer within the Griffins Landing Member intercepted by the wells H-BOR-34 and H-BOR-50. To determine if this conductive low-velocity target is connected between the wells H-BOR-34 and H-BOR-50, we analyzed the seismic waves recorded at the depths of $140 \mathrm{ft}-150 \mathrm{ft}$ for the presence of trapped waves. Since there is a P-wave velocity contrast between the target of interest and the host medium, trapped seismic energy in the form of leaky modes was detected using time-frequency analysis. In fact, the group velocity plot calculated from waveforms records for the detector at $140 \mathrm{ft}$. where the source was placed at $140.5 \mathrm{ft}$ exhibits $\mathrm{P}$-wave spectral components which contain low- and highfrequency distributions (see Figure $7 \mathrm{~b}$ ).

In a similar manner we analyzed the data associated with the green clay layer to determine if this layer is connected between wells $\mathrm{H}-\mathrm{BOR}-34$ and H-BOR-50. In this case the common detector seismogram for the depth of $200 \mathrm{ft}$ was considered for the analysis. Several waveforms recorded when the source was placed above, below and within the green clay layer were processed using time- 
frequency representations. The group velocity contour plots of these waveforms did not show evidence of trapped seismic energy. The time-frequency analysis of the 3-component seismic data recorded at the detector position of $200 \mathrm{ft}$ suggests that the conductive material (green clay) intercepted by H-BOR-34 and H-BOR-50 is not connected between these wells, or that the detector was not placed in the green clay layer. For example, a detector placed in the low-velocity zone at a depth of $205 \mathrm{ft}$ may coupled better to the formation than a detector placed at $210 \mathrm{ft}$ to detect trapped seismic energy associated with the green clay layer. Indeed, to test this concept in more detail it will require to take more 3-component measurements at several detector positions above and below and within the green clay layer to thoroughly determine if guided waves can be detected in this zone.

An additional interpretation was made by comparing the velocity profiles given in Figure 8 with the resistivity and gamma ray logs given in Figures 4 and 5 . The maximum resistivity anomaly observed between the depths of $150 \mathrm{ft}$ to $180 \mathrm{ft}$ in well $\log \mathrm{H}-\mathrm{BOR}-50$ correlated with a local maximum P-wave velocity anomaly and a low-gamma count. In this zone, the natural gamma count is low and the resistivity and the P-wave velocity are high. These petrophysical characteristics are typical of those of carbonate rocks. In addition, the resistivity log of well H-BOR-34 shows a small resistivity anomaly which may correspond to a heterogeneity not associated with carbonate rock.

The top and bottom of the carbonate rock at a depth of about $170 \mathrm{ft}$ correlates with reflections observed in the reflection image plots in Figure 10. This reflection image shows that the carbonate has been intercepted by sands and other lateral changes of the region of interest. A weak reflection is observed at the depth of $145 \mathrm{ft}$ which correlates with the tan clay unit. In addition, in the upper portion of the reflection image, two reflections are observed. The first reflection is at a depth of about $55 \mathrm{ft}$, which is associated with the boundary between the Tobacco Road Formation 
and the Upper Dry Branch Formation. The second reflection is observed at a depth of about $85 \mathrm{ft}$, an it correlates with the Lower Dry Branch Formation.

\section{Integration of Travel Time Tomograms and Reflection Imaging}

Travel times acquired from the H-BOR-34 and H-BOR-50 survey were inverted to produce a velocity tomogram. This tomogram has delineated the lateral and vertical heterogeneous conditions of the formation between the depths of 140 and $200 \mathrm{ft}$. In particular, the lateral contact between the carbonate (intercepted by well $\mathrm{H}-\mathrm{BOR}-50$ ) and the fully saturated sediments (intercepted by well $\mathrm{H}$ BOR-34) is captured in the high-resolution traveltime tomogram given in Figure 11. These results are similar to those determined by Majer et al. (1995). Majer also inverted the seismic amplitudes recorded between wells H-BOR-50 and H-BOR-34 to produce an attenuation tomogram.

The carbonate is a higher velocity unit and the water saturated sands are much lower velocity zones. In addition, the carbonates are associated with a low quality factor and the water saturated sands are associated with a higher quality factor (see Majer et al. 1995). Since the heterogenous carbonate unit is porous and vuggy the fluid will flow in and out of the porous when the waves propagate through the carbonate matrix. Under this conditions energy loss will occur by reducing the wave amplitude as the wave travels between wells. Alternatively, the low velocity zone formed by fully saturated sands will not allow the fluid to flow in and out of a more uniform sand matrix, as a consequence no energy loss will occur by the presence of the fluids in the sands. Indeed energy losses may occur by the presence of viscoelasticity in the sands or any other material present in the formation. In the present application we expect that the viscoelastic losses will be much less than those associated with fluid flow.

The integration of the velocity tomogram and the P-wave reflection imaging has yielded a final characterization of the subsurface in the region under study (see Figures 10 and 11). In these plots 
the soft sands delineated by the velocity tomogram as a blue zone (between 22 to $140 \mathrm{ft}$ in the horizontal direction) are surrounded by reflection events observed between depths of $150 \mathrm{ft}$ and $200 \mathrm{ft}$ in the reflection imaging. These reflection events were originated by the acoustic impedance contrast between the low velocity zones of "soupy" sand mixtures (unconsolidated materials) and the more rigid and dense (competent) surrounded medium .

\section{CONCLUSIONS}

The integration of well logs and the 3-component seismic data as well as the reflection image delineated a clay layer within the Griffins Landing Member, and the carbonate rock units. The rotation of the 3-component data indicated the presence of trapped seismic energy associated with the connectivity of the tan clay layer between wells H-BOR-34 and H-BOR-50. On the other hand, the results of the interpretation suggested that there is not sufficient data to prove whether the green clay unit is connected or not.

In general, the Santee sediments are associated with a large velocity low relative to the Dry Branch (above) and Congaree (below) high-velocity formations. In several, this low-velocity anomaly a P-wave velocity which correlates with the resistivity logs. A local P-wave velocity and resistivity maxima correlates with the carbonate rocks which are associated with low-gamma ray counts. In addition, the large velocity anomaly is consistent with the compressional wave velocity logs given in Figures 4 and 5. Compressional wave velocities less than the compressional wave velocity of the water (in shallow geophysical applications) is not unusual in low shear-wave velocity formations having bulk densities greater than the density of the water.

The processing and analysis of the seismic data suggested that additional 3-component seismic measurements should be conducted at shorter spacing to resolve the heterogeneities within the Santee 
Limestone formation, and to determine whether the green clay unit is continuous between wells, and to predict other lithologic features of interest.

The combined P-wave reflection imaging and the travel time velocity tomogram has delineated a large soft zone of sand mixtures (in the inter-well area between wells H-BOR-50 and H-BOR-34) at a depth of $150-200 \mathrm{ft}$. The length of the soft zone is $120 \mathrm{ft}$ between wells H-BOR-50 and H-BOR34 , and the extension of this zone beyond well H-BOR-34 is unknown.

\section{ACKNOWLEDGMENTS}

This work was supported by the Westinghouse Savannah River Company, Subcontract number AB6239N. The conclusions and opinions of the authors do not necessarily reflect those of the United States Department of Energy. 


\section{REFERENCES}

Balogh, W.T., Owen, T.E., and Harris, J.M. (1988). "A new piezoelectric transducer for hole-tohole seismic applications," Expanded Abstracts, Paper DEV2.5 58th Ann. Int'l. Meeting SEG; Anaheim, CA; Oct. 30-Nov. 3.

Barr, F.J., Beasley, T.R., and Piggin, R.H. (1989). "Method and apparatus for seismic exploration of strata surrounding a borehole," U.S. Patent No. 4,873,675.

Becquey, M., Bermet-Rollande, J.O., Laurent, J., and Noual, G. (1992). "Imaging reservoirs -- A cross-well seismic experiment, "First Break (EAEG), Vol. 10, pp. 337-344.

Chen, S.T., (1993). "A Single-well profiling tool and tube wave suppression system", Expanded Abstracts, Paper BG1.4, 63rd Ann. Int'l Meeting SEG, Washington, DC.

Chen, S.T., Zimmerman, L.J., and Tugnait, J.K. (1990b). "Subsurface imaging using reverse VSP and cross-hole tomographic methods, "Geophys., Vol. 55, pp. 1478-87.

Cohen, L., (1989). “Time-Frequency Distributions - A Review," Proc. IEEE, Vol. 77, No. 7, 941981.

Hardage, B.A. (1992). Cross-Well Seismology and Reverse VSP, Geophysical Press, Ltd. London. Hlawatsch, F., and Boudreaux-Bartels, G.F., (1992). "Linear and Quadratic Time-Frequency Signal Representations," IEEE Signal Processing Mag., Vol. 9, 21-67.

Jackson, M.J., and Tweeton, D.R., (1994). "MIGRATOM-Geophysical Tomography using Wavefront Migration and Fuzzy Constraints," Report of Investigations \#9497, Bureau of Mines, United States Department of Interior.

Journel, A.G. (1989), "Fundamentals of geostatistics in five lessons," American Physical Union, Washington, DC, Vol. 8. 
Kennedy, W.S., Wiggins, W., and Aronstam, P. (1988). "Swept-frequency borehole source for inverse VSP and cross-borehole surveying," Expanded Abstracts, Paper DEV2.6; 58th Ann. Int'l. Meeting SEG; Anaheim, CA, Oct. 30-Nov. 3..

Laurent, J., Layotte, P.C., Meyneir, P. and Noual, G. (1990). "A mechanical wall-clamped borehole source and its use in inverse VSP and cross-hole seismic surveying, "Abstracts, Paper 13-19; 52nd Meeting EAEG; Copenhagen, Denmark; 28 May - 1 June.

Lazaratos, S.K., Langan, R., and Harris, J.M. (1994). "Shear-wave crosswell reflection imaging in West Texas," Expanded Abstracts, Paper DP3.2, Ann. Int'l Meeting SEG, Los Angeles, CA, October 23-27.

Majer, E., Peterson, J., Hubbard, S., Daley, T., and Vasco, D., (1995). "Evaluation of the applicability of high resolution crosshole seismic imaging beneath the H-Tank area for geomechanical properties" Final Report, Lawrence Berkeley Laboratory, Berkeley, California.

Majer, E., Peterson, J., Hubbard, S., Daley, T., and Vasco, D., (1995). "Evaluation of high resolution crosshole seismic imaging beneath the H-tank area for geomechanical properties," Final Report, Lawrence Berkeley National Laboratory, Berkeley, California.

Mosher, C.C. and Mason, I.M., (1983). "Borehole-to-borehole seam-wave transmission," Expanded Abstracts, Paper C1.4, 53rd Ann. Int'l Meeting SEG, Las Vegas, NV, Sept. 11-15.

Owen, T.E. and Shirley, D.J. (1985). "Cylindrical bender-type vibration transducer," U.S. Patent No. $4,525,645$.

Parra, J.O., and Xu, P-C., (1994), "Dispersion and attenuation of acoustic guided waves in layered fluid-filled porous media," J. Acoust. Soc. Am., 95, 91-98.

Parra, J.O., (1995). “A feasibility study of high-resolution reverse VSP and interwell seismic methods for hydrocarbon reservoir characterization," The Log Analyst, May-June, 64-81. 
Raytheon Engineers and Constructors, (1994). "Geophysical investigations, in-tank precipitation facility, Task 176", Final Report, Westinghouse Savannah River Company Project Engineering Service Contract.

Rowe, P. and Mason, I.M., (1982). "Downhole recharged electrolytic sleeve exploder," Expanded Abstracts, Paper S14.8, 52nd Ann. Int'l Meeting SEG, Dallas, TX, Oct. 17-21.

Staron, P., Arens, G., and Gros, P. (1988). Method of instantaneous acoustic logging within a borehole," U.S. Patent No. 4,718,048.

Snipes, D.S., Fallaw, W.C., Price, V., and Cumbest, R.S., (1993). The pen branch fault: Documentation of late cretaceous-tertiary faulting in the coastal plain of South Carolina: Southeastern geology, 33, 195-218.

Zook, B.J., (1994). “Using Guided Waves to Characterize Gas Reservoir Continuity, Phase I: Data Processing," Topical Report \#GRI-94/0384.2, Gas Research Institute. 


\section{LIST OF CAPTIONS}

Figure 1. The upper Atlantic coastal plain of South Carolina and Georgia.

Figure 2. A simplified cross-section of the In-Tank Precipitation site geology at the Savannah River Site.

Figure 3. A plan view of the five wells at the In-Tank Precipitation site.

Figure 4. Display of resistivity logs for wells H-BOR-34, H-BOR-50, and H-BOR-44.

Figure 5. Display of gamma ray logs for wells H-BOR-34, H-BOR-50, and H-BOR-44.

Figure 6. A common receiver particle velocity seismogram for a detector depth of $140 \mathrm{ft}$. The seismic data was produced using a 1200 Joule arc discharge source and a shuttle 3component detector.

Figure 7a. Time-frequency spectrogram of a trace recorded at the source depth of $160.5 \mathrm{ft}$, given in the seismogram of Figure 6.

Figure $7 \mathrm{~b}$. Time-frequency spectrogram of a trace recorded at the source depth of $145.5 \mathrm{ft}$, given in the seismogram of Figure 6.

Figure 7c. Time-frequency spectrogram of a trace recorded at the source depth of $138 \mathrm{ft}$, given in the seismogram of Figure 6.

Figure 7d. Time-frequency spectrogram of a trace recorded at the source depth of $129 \mathrm{ft}$, given in the seismogram of Figure 6.

Figure 8. Compressional wave velocity profile derived from three-component detector data.

Figure 9. A common receiver pressure seismogram for a hydrophone depth of $205 \mathrm{ft}$. The seismic data was produced using a piezoelectric source and an array of hydrophones.

Figure 10. Comparison of down going reflection image with resistivity and gamma ray logs from wells $\mathrm{H}-\mathrm{BOR}-50$ and H-BOR-34.

Figure 11. P-wave velocity tomogram showing a low-velocity zone formed by soft materials. 

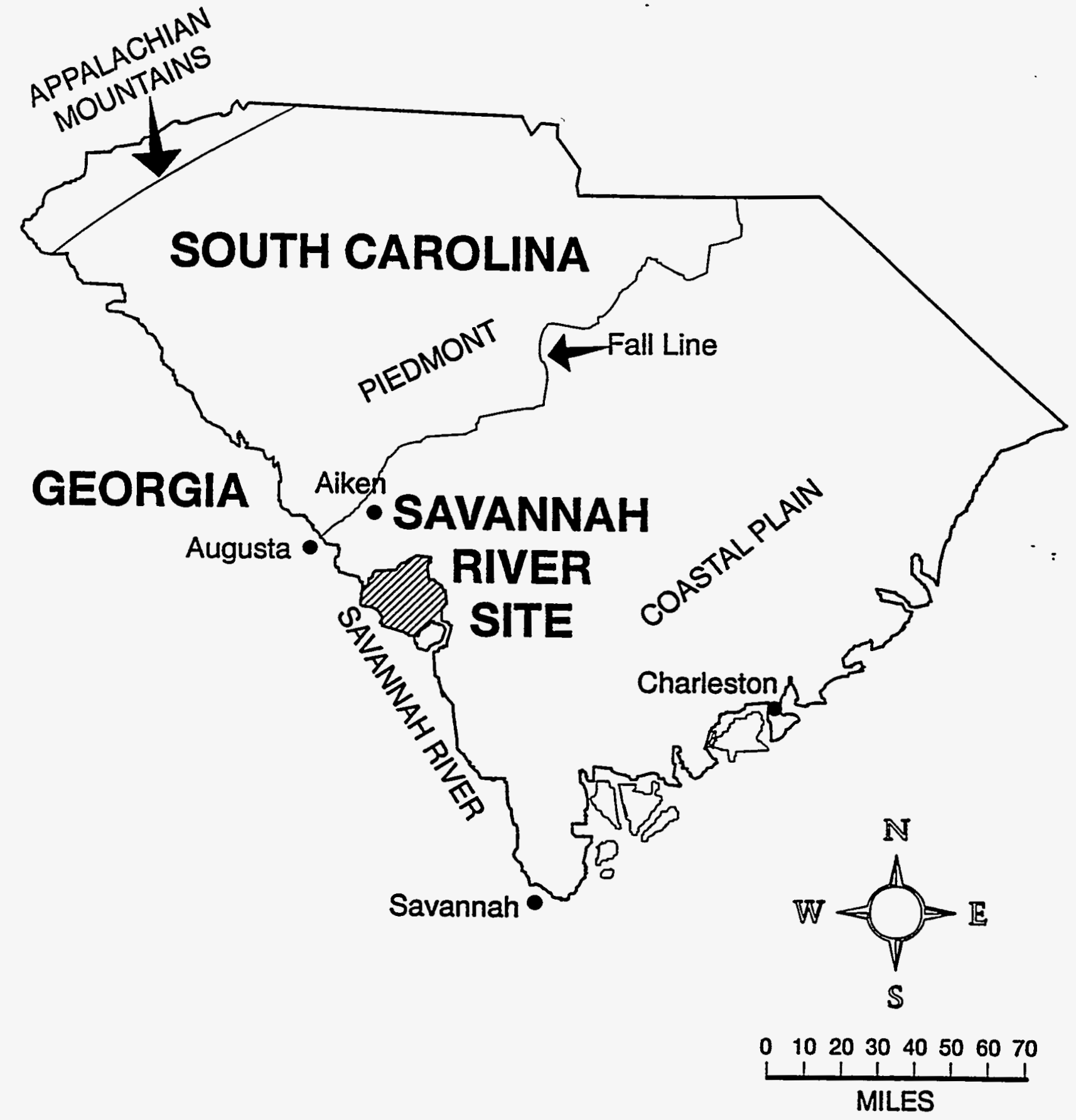

$\stackrel{1}{0} \quad 25 \quad 50_{\text {KILOMETERS }}^{1}$

Figure 1 


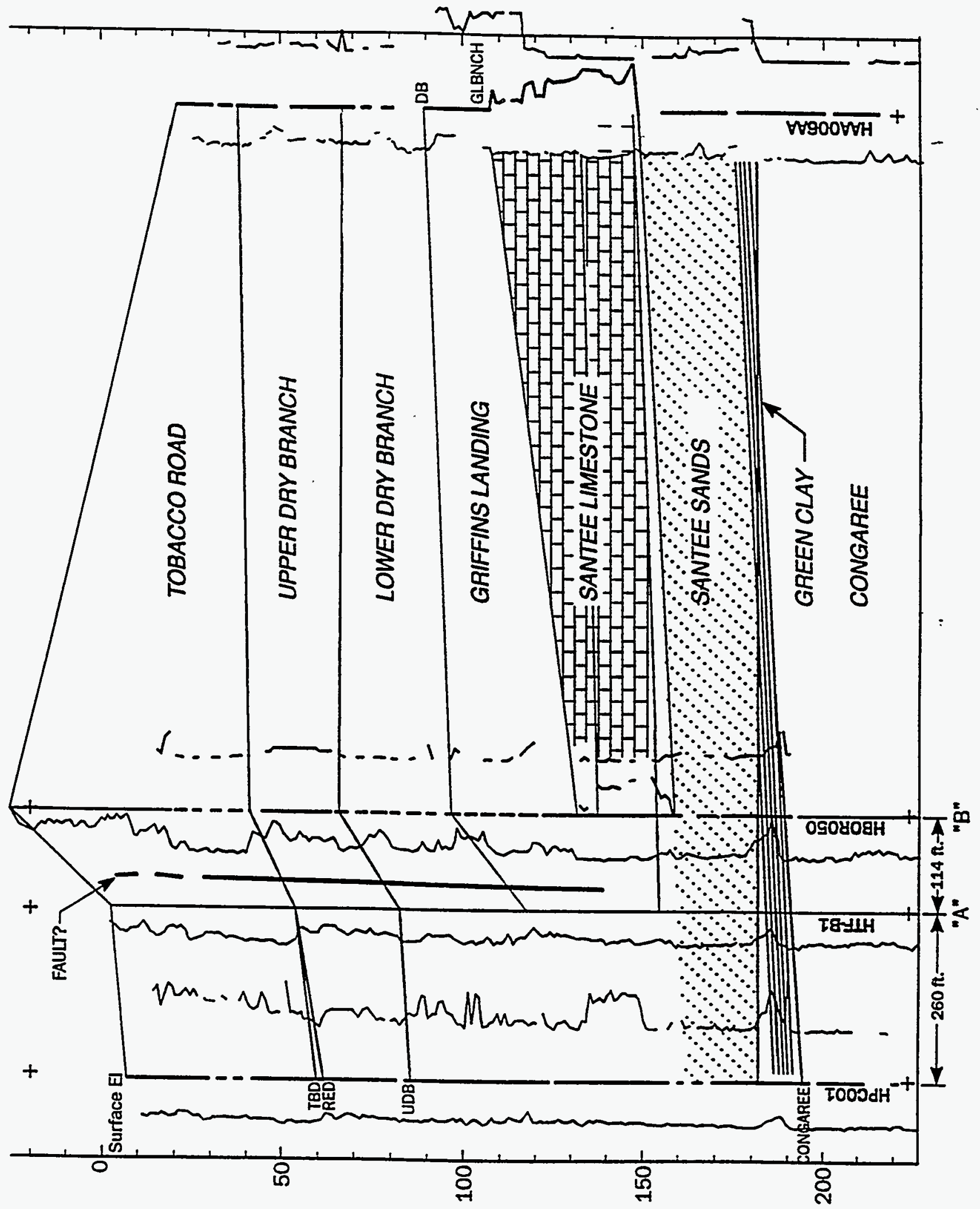

Figure 2 


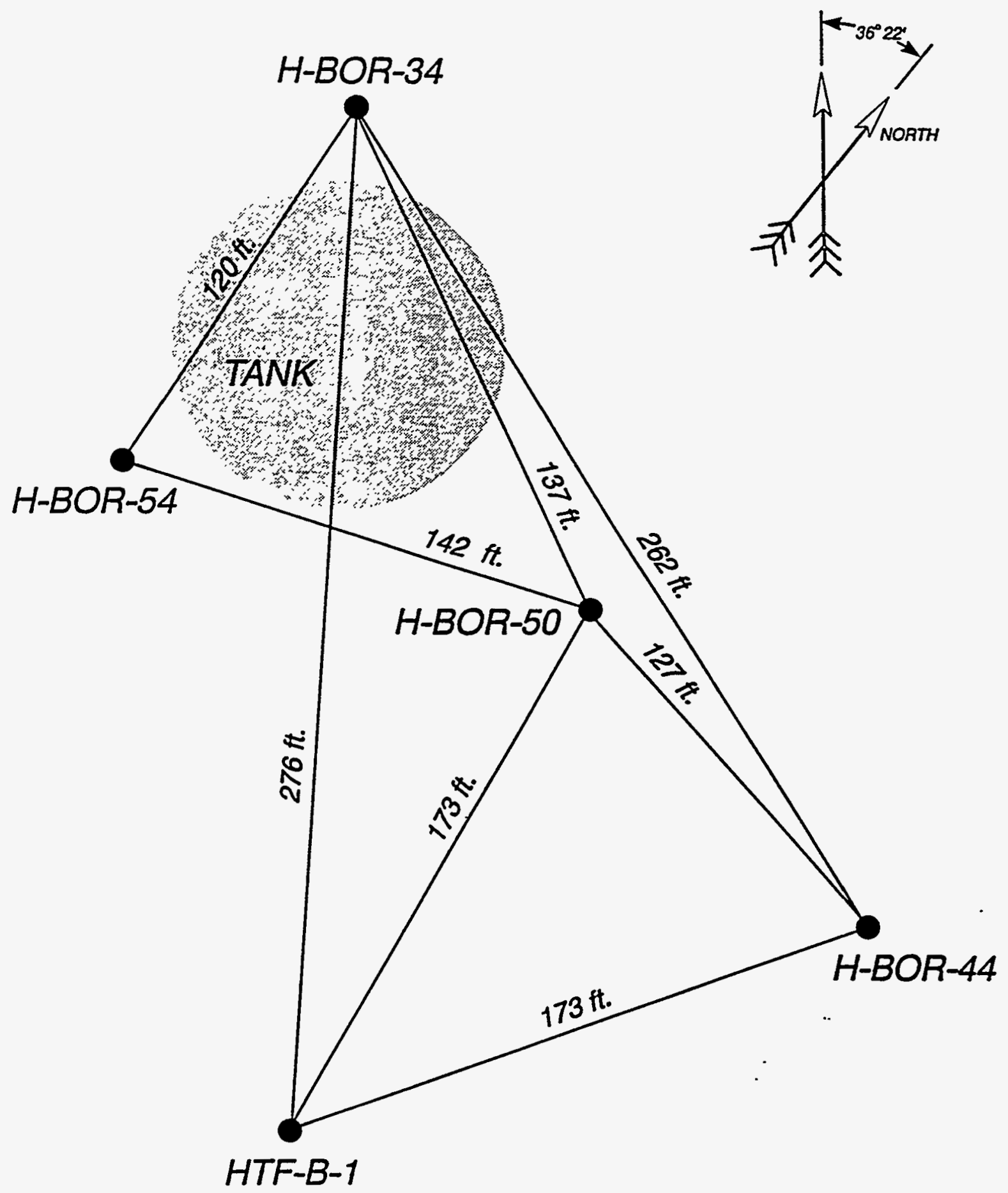

Figure 3 


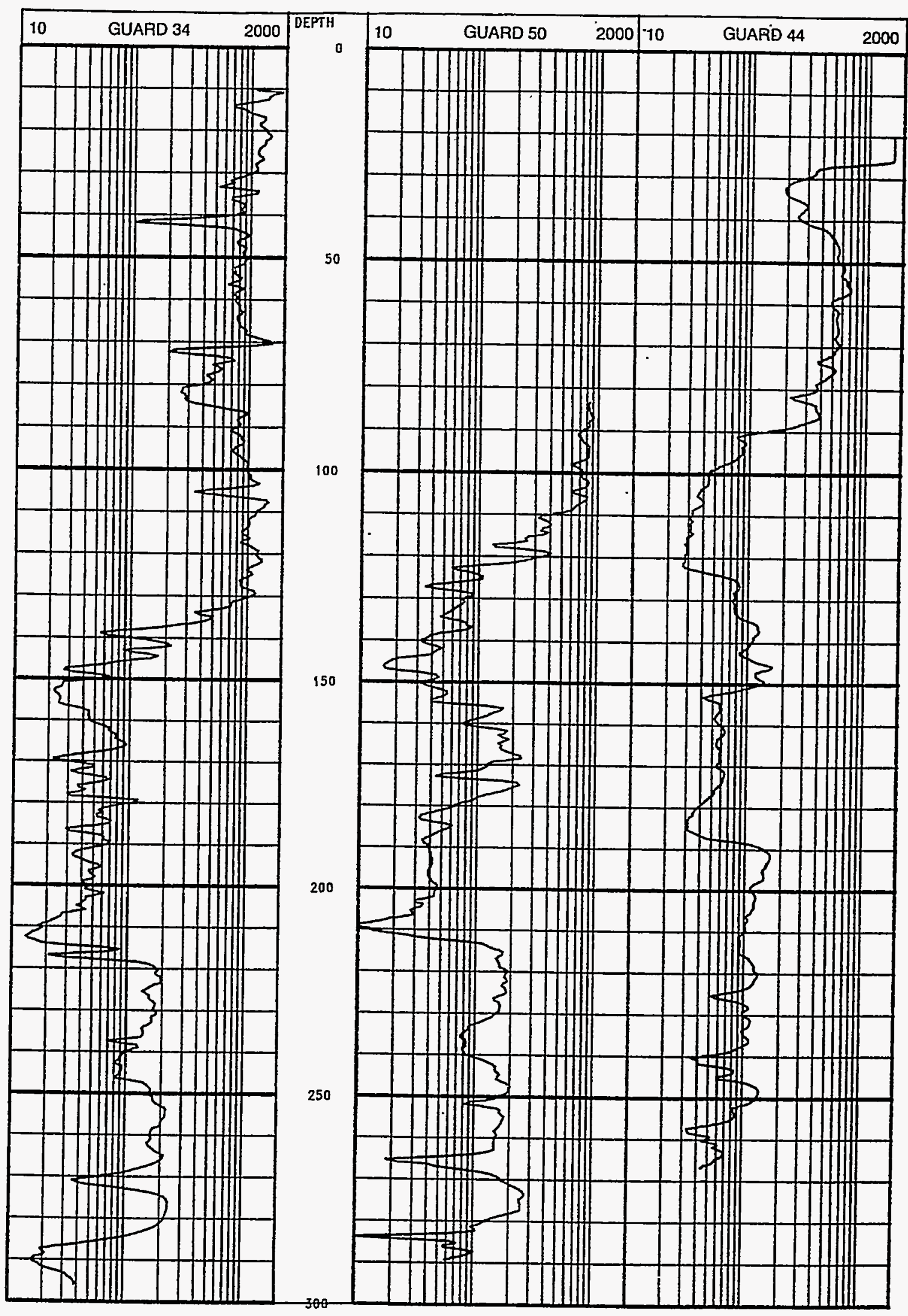

Figure 4 


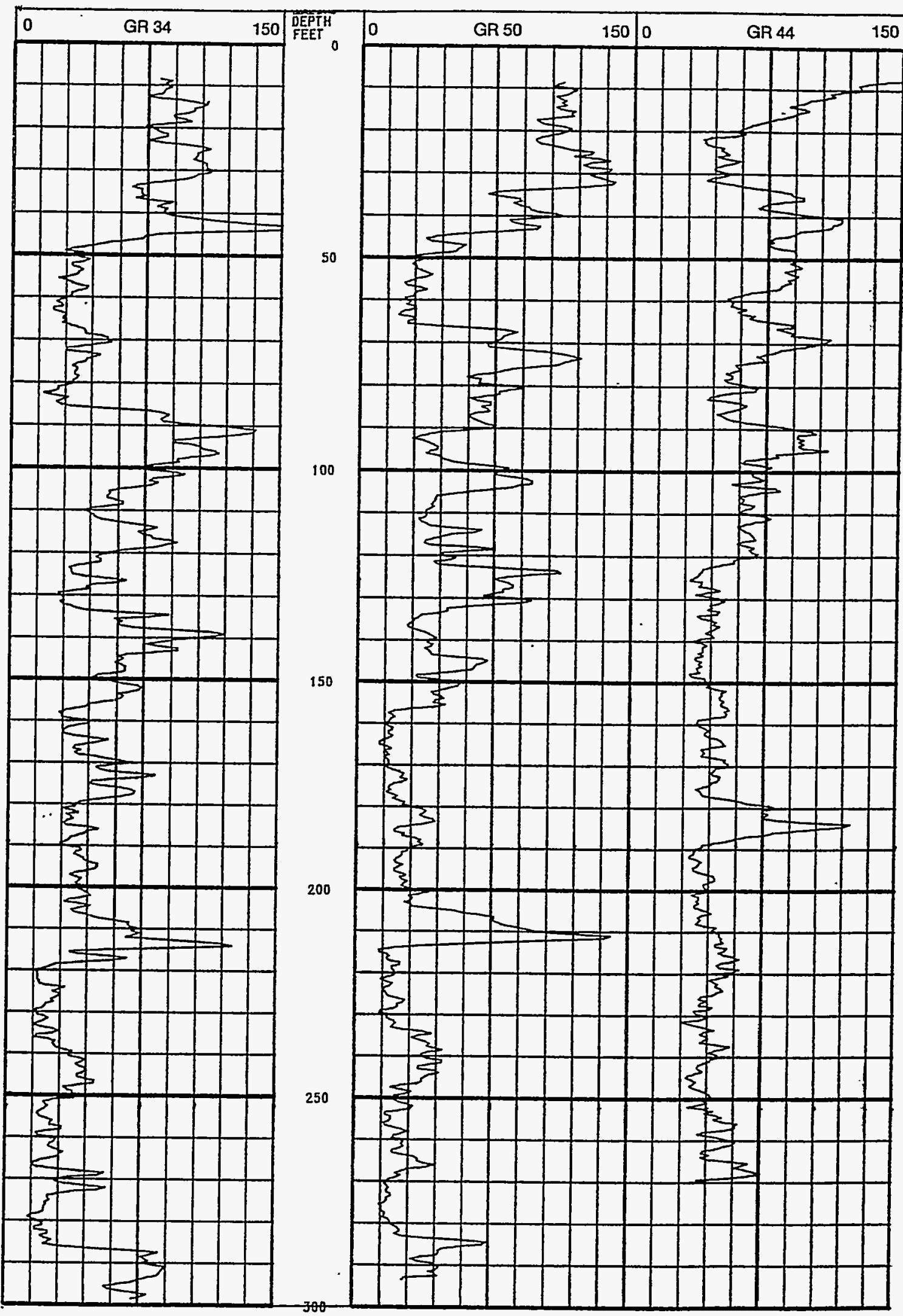

Figure 5 


\section{Savannah River Data}

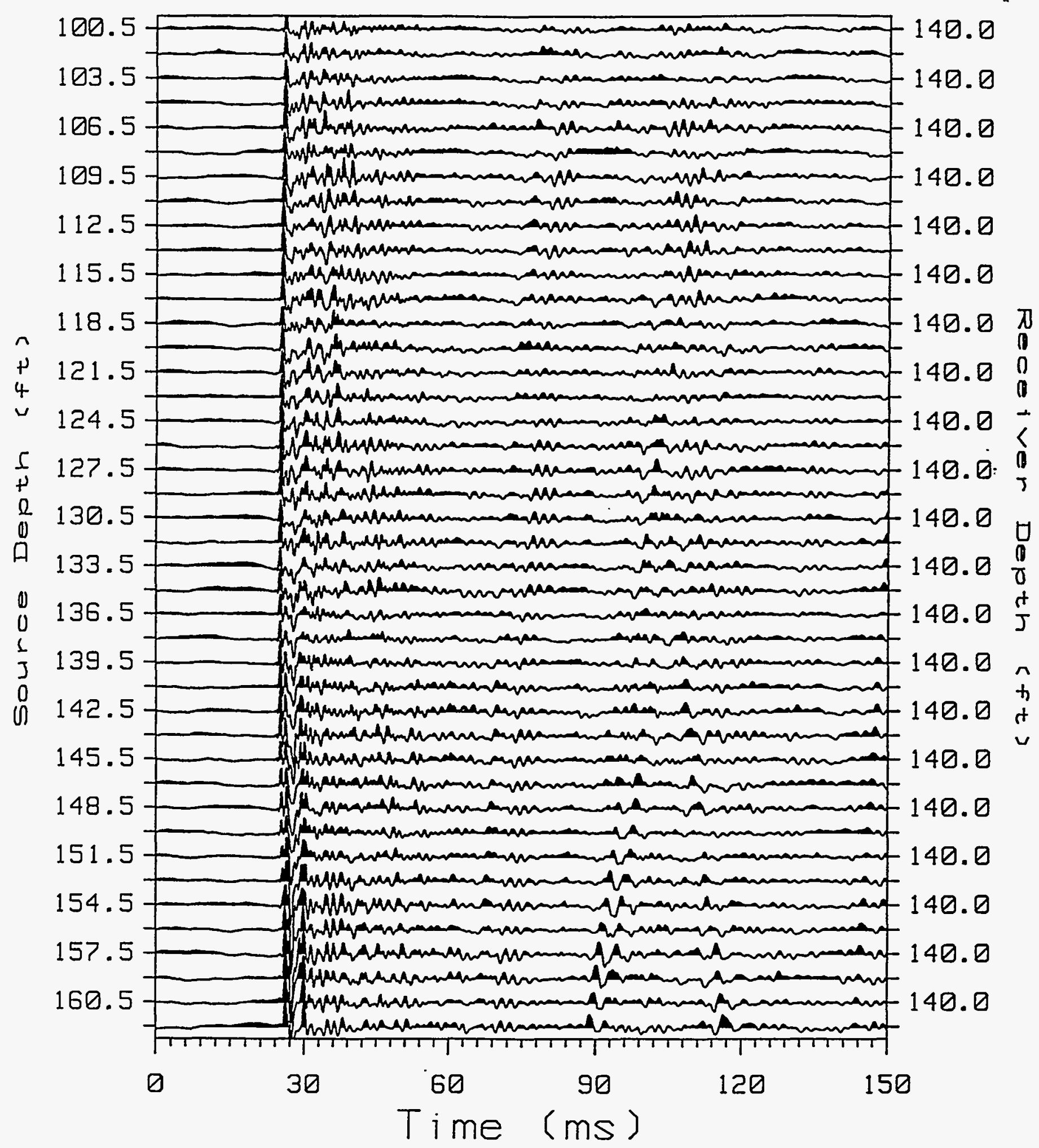

Figure 6 


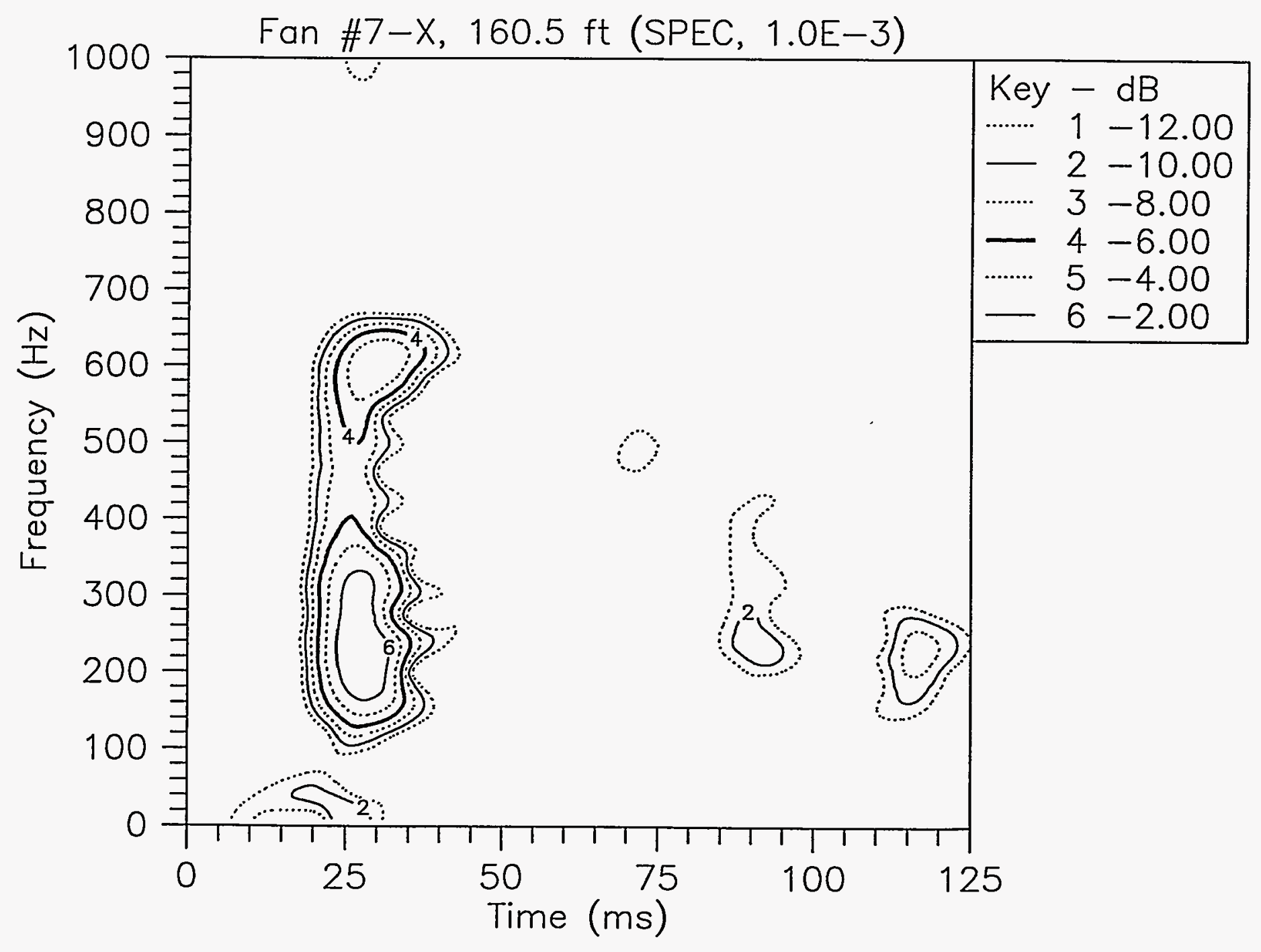

Figure 7a 


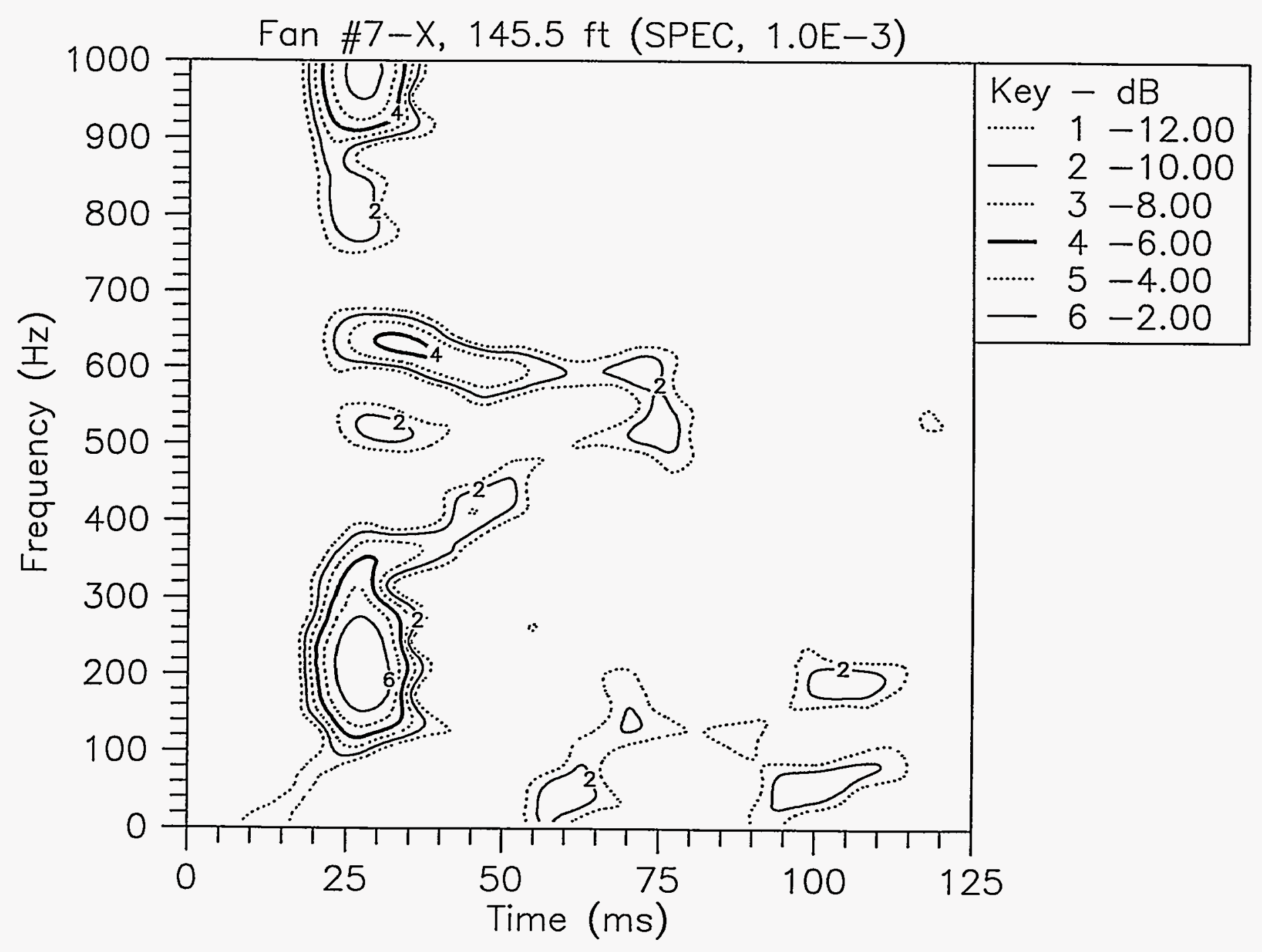

Figure $7 b$ 


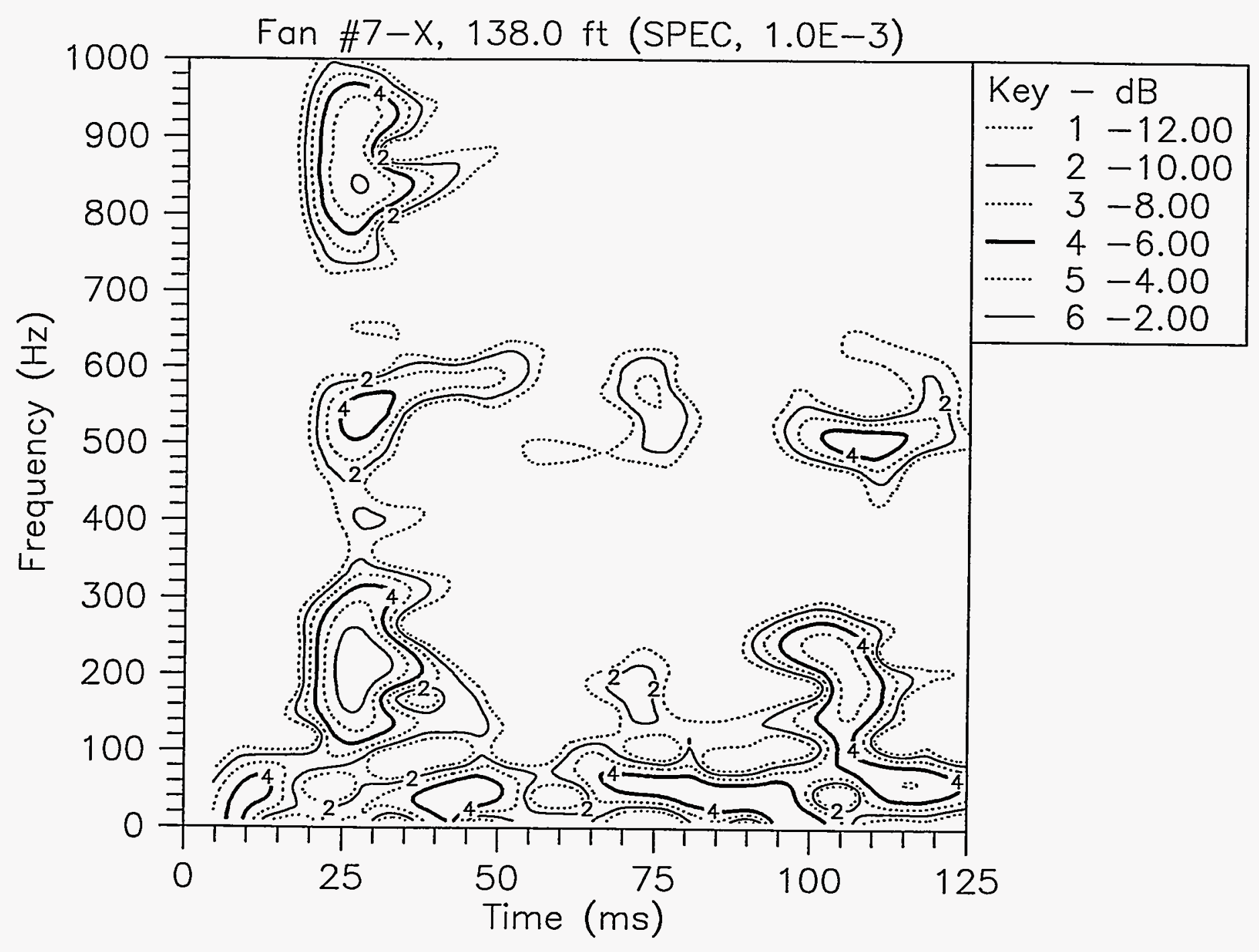

Figure 7c 


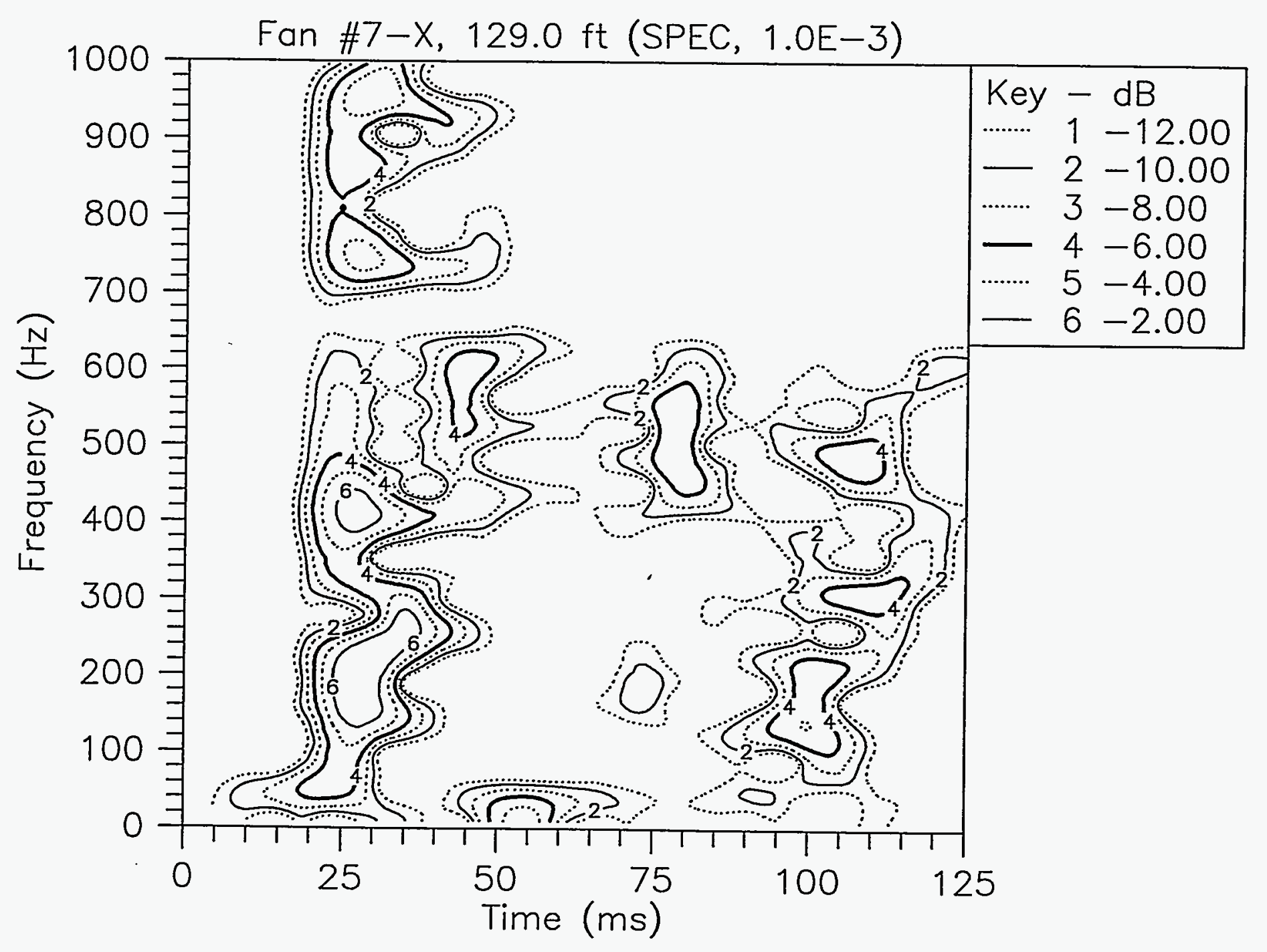

Figure 7d 

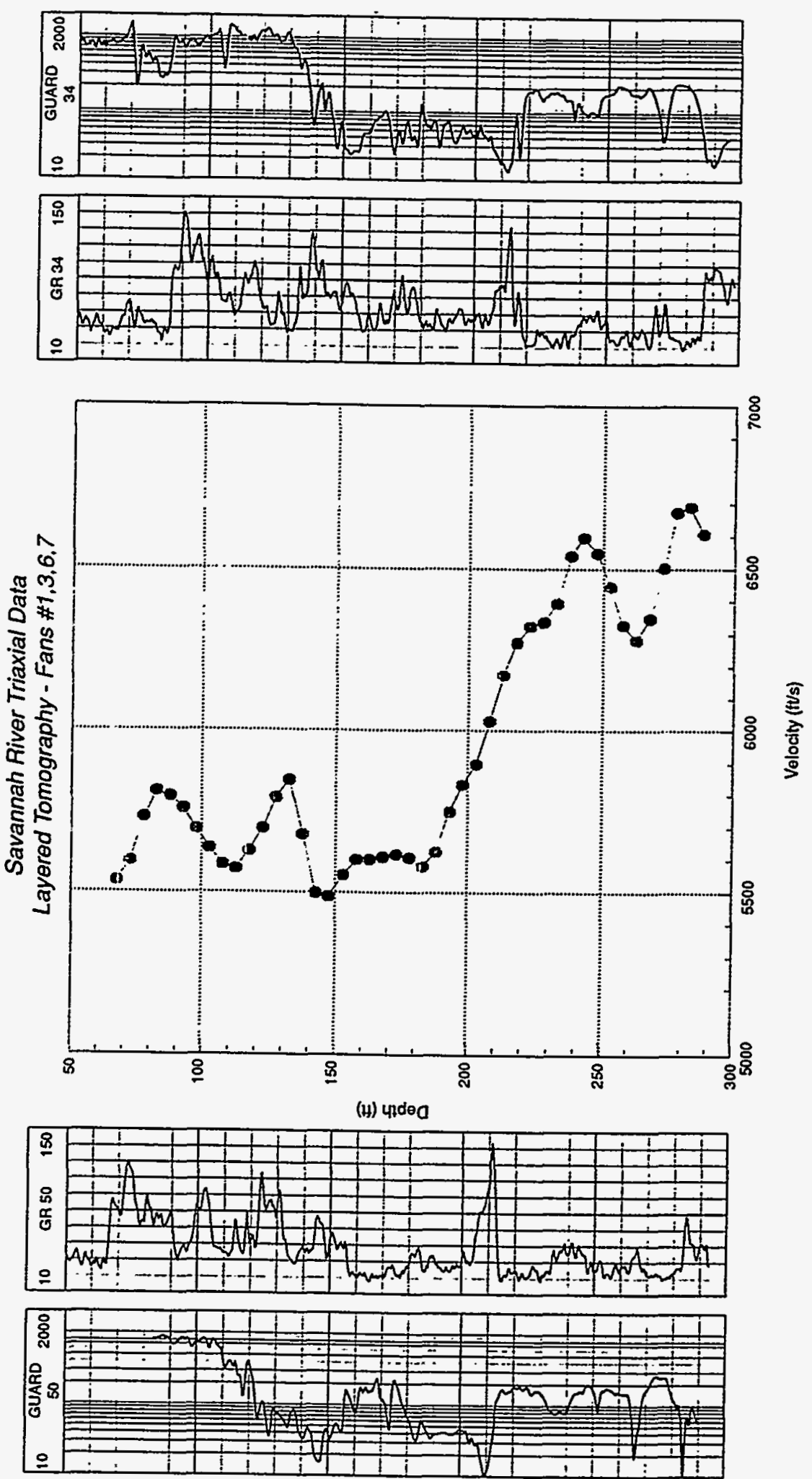

Figure 8 


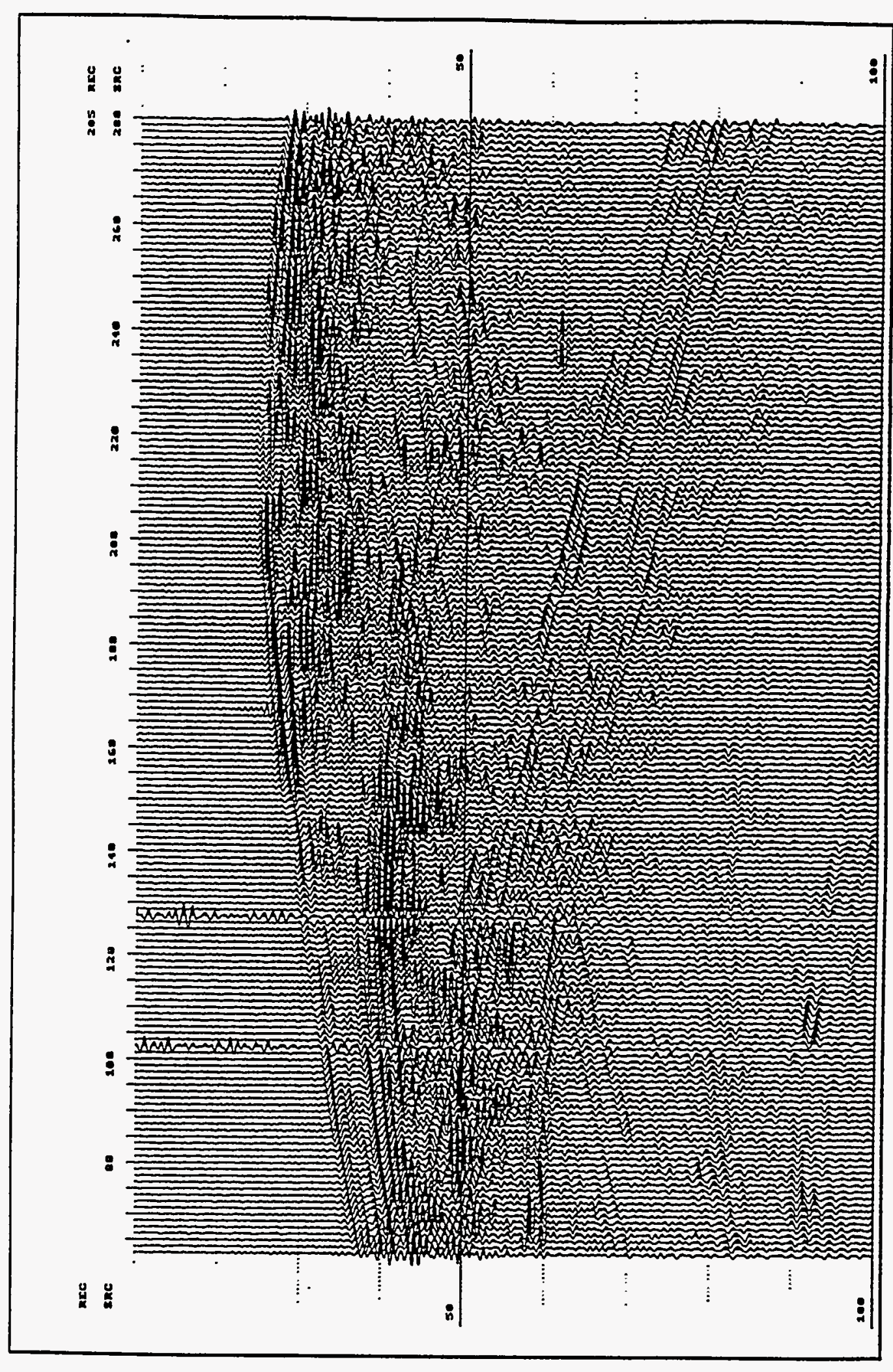

Figure 9 


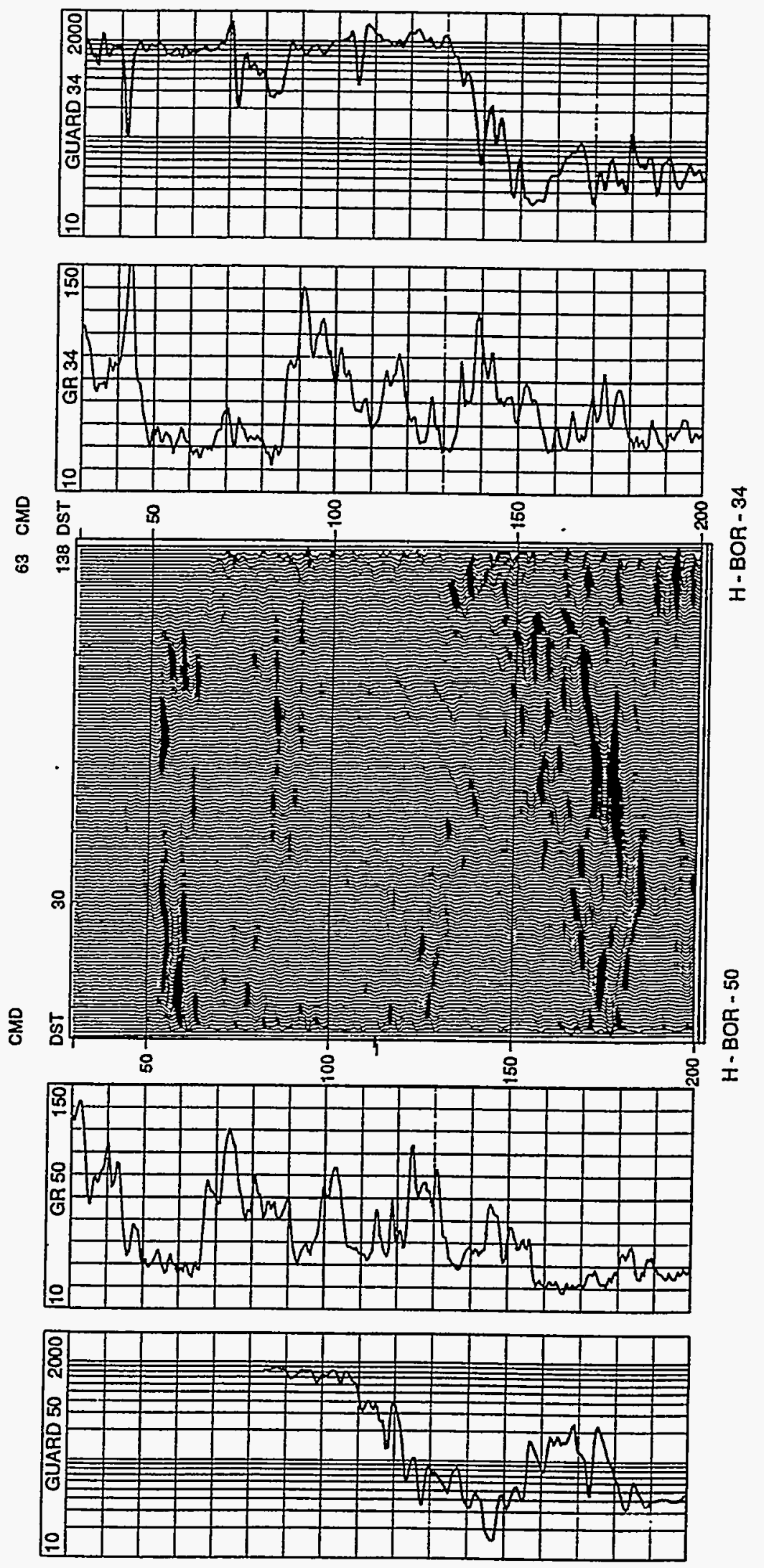

Figure 10 


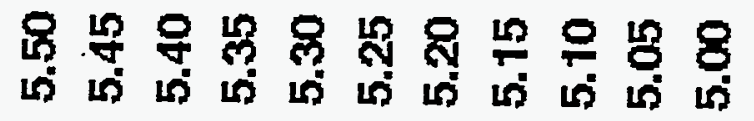

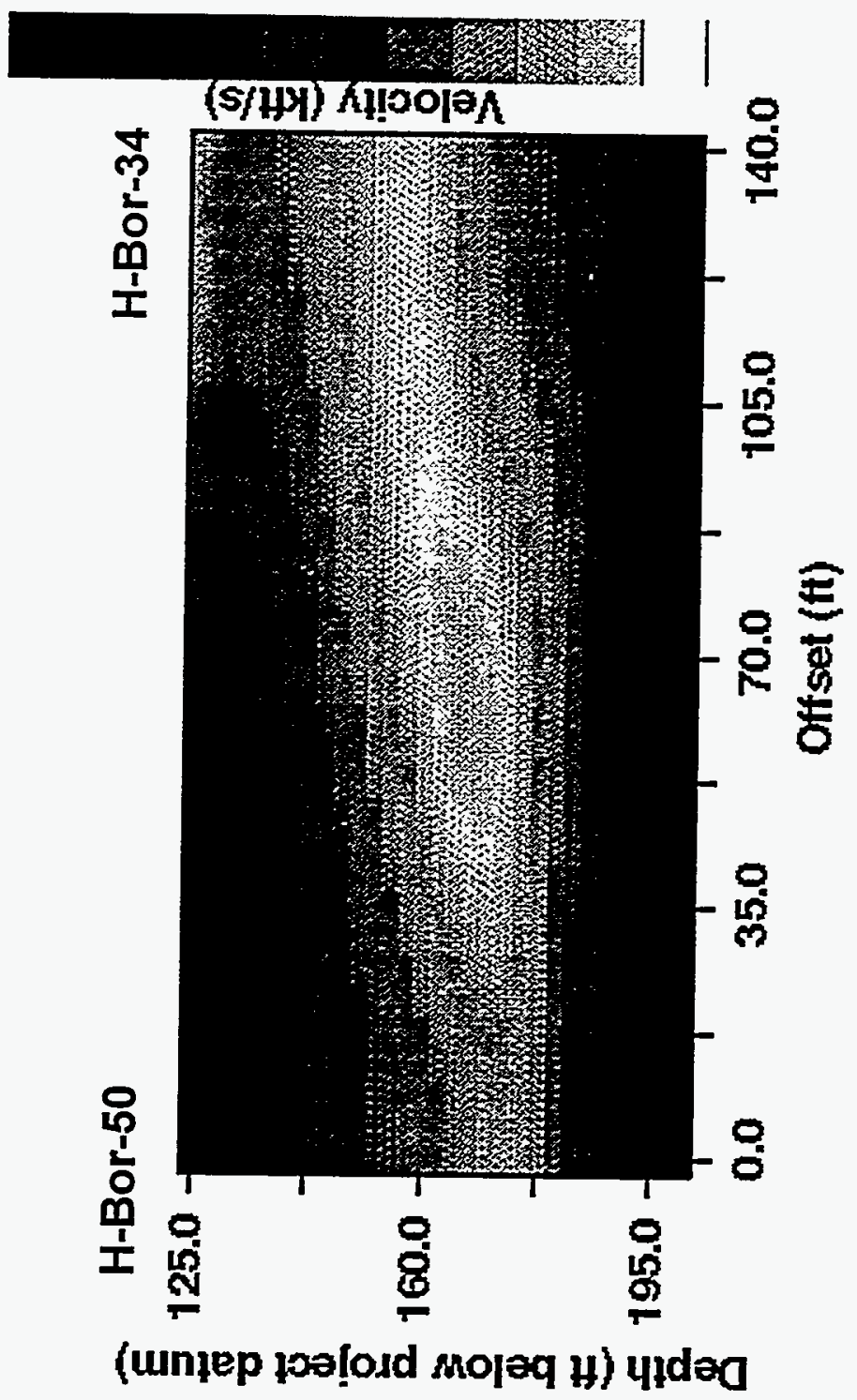

Figure 11 